\title{
HYPERTROPHIC CARDIOMYOPATHY WITH PARTIAL ANOMALOUS PULMONARY VENOUS CONNECTION AND ATRIAL SEPTAL DEFECT: A RARE PRESENTATION
}

\author{
ALPHONSA $\mathbf{M}^{1}$, KARTHIK R ${ }^{2}$, SATISH CG ${ }^{3}$, NAVIN PATIL ${ }^{4 *}$, BALAJI $0^{4}$, RAHUL KOTIAN $^{5}$
}

${ }^{1}$ Department of Echocardiography, Narayana Institute of Cardiac Science, Bengaluru, Karnataka, India. ${ }^{2}$ Department of Internal Medicine, Kasturba Medical College, Manipal University, Manipal, Karnataka, India. ${ }^{3}$ Department of Non-interventional Cardiology, Fortis Hospital, Bengaluru, Karnataka, India. ${ }^{4}$ Department of Pharmacology, Kasturba Medical College, Manipal, Karnataka, India. ${ }^{5}$ Department of Medical Imaging, School of Allied Health Sciences, Manipal University, Manipal, Karnataka, India. Email: navin903@gmail.com

Received: 27 March 2017, Revised and Accepted: 03 May 2017

\section{ABSTRACT}

Hypertrophic cardiomyopathy (HOCM) is characterized by heterogeneous clinical expression, unique pathophysiology, and diverse natural history. Coexistence of arterial septal defect and partial anomalous pulmonary venous connection (PAPVC) is very rare. Since HOCM is a congenital defect, coexistence of other congenital defects should be kept in mind when we treat the patients. Only very few cases of HOCM with coexisting congenital anomalies have been reported so far in medical literature. Hence, we report a case of HOCM with atrial septal defect and PAPVC in a 49-year-old male patient.

Keywords: Hypertrophic cardiac myopathy, Atrial septal defect, Coronary artery disease, Anomalous pulmonary venous connection.

(C) 2017 The Authors. Published by Innovare Academic Sciences Pvt Ltd. This is an open access article under the CC BY license (http://creativecommons. org/licenses/by/4. 0/) DOI: http://dx.doi.org/10.22159/ajpcr.2017.v10i8.18739

\section{INTRODUCTION}

Hypertrophic cardiomyopathy (HOCM) is a well-known myocardial disease caused by a multitude of mutations in genes encoding proteins of the cardiac sarcomere [1-5]. HCM is characterized by heterogeneous clinical expression, unique pathophysiology, and diverse natural history [6-13]. However, the additional coexistence of an atrial septal defect (ASD) and partial anomalous pulmonary venous connection (PAPVC) is quite rare. Hence, we report a case of HOCM with ASD and PAPVC in a tertiary care hospital in India.

\section{CASE REPORT}

Informed consent was obtained from the patient. A 49-year-old male with HOCM was admitted to our hospital with complaints of gradually progressive breathlessness, angina, and exertional syncope. He had the history of systemic hypertension and bronchial asthma. He had undergone coronary angiogram 1 year before, which reveals a single vessel disease of ramus intermedius with $50 \%$ proximal stenosis and he was advised on medical management and surgical myectomy if symptoms persist. On physical examination, blood pressure was 133/88 $\mathrm{mmHg}$, heart rate was $53 \mathrm{bpm}$. A 12-lead electrocardiogram revealed a left ventricular (LV) hypertrophy with strain pattern. Echocardiography showed features of hypertrophic obstructive cardiomyopathy, the presence of PAPVC, coronary artery disease (CAD), and a doubtful sinus venosus ASD. He had an LV peak pressure gradient of $60 \mathrm{mmHg}$, LV mid cavity, and apical gradients of 5-10 mmHg; LV apex showed increased hypertrophy with near systolic LV cavity, obliteration at mid-cavity and apex. Anteroseptum showed a thickness of $16-18 \mathrm{~mm}$ at the basal level and $18-22 \mathrm{~mm}$ at the mid-level, posterior wall had a thickness of $14 \mathrm{~mm}$, inferoseptum demonstrated the thickness of $14 \mathrm{~mm}$ at the basal level and with thickness of $16 \mathrm{~mm}$ at the midlevel. Lateral wall thickness was found to be $13 \mathrm{~mm}$, whereas inferior wall had a thickness of $13 \mathrm{~mm}$ and anterior wall of $14 \mathrm{~mm}$. There was mild tricuspid regurgitation with increases pulmonary artery systolic pressure of $40 \mathrm{mmHg}$, mild functional mitral regurgitation (MR), minimal amount of pericardial effusion, and an adequate LV systolic function with an ejection fraction (EF) of 50-55\% by three-dimensional echocardiography method.
Magnetic resonance imaging revealed a non-dilated LV with EF of $76 \%$, concentric hypertrophy with systolic arterial motion causing significant left ventricular outflow tract narrowing, patchy fibrosis in the hypertrophied segments, apical cavity obliteration and right PAPVC (Fig. 1). Laboratory analysis showed abnormal kidney function test with creatine $(9 \mathrm{mg} / \mathrm{dl})$ urea nitrogen $\left(95.33 \mathrm{~mL} / \mathrm{min} / 1.73 \mathrm{~cm}^{2}\right)$. All other parameters were normal. Patient has undergone a test for hepatitis B antigen, anti-hepatitis C virus antibody, and HIV (chemiluminescence) in which all showed negative results. Prescribed medications included tablet propranolol $40 \mathrm{mg}$ thrice daily, atorvastatin $10 \mathrm{mg}$ daily, aspirin $75 \mathrm{mg}$ daily, and amlodipine $5 \mathrm{mg}$ daily.

Patient underwent transaortic and transventricular septal myectomy, PAPVC rerouting and ASD closure. In the procedure, midline sternotomy was done, thymus dissected, and pericardium opened. Heparin was given and went on bypass by bicaval cannulation and aortic cannulation. Cardioplegia was given through aortic root and heart was arrested in diastole. Right atrium was opened and using two-patch technique PAPVC rerouting and ASD closure was completed.

Using lazy "s" incision aorta opened and cardioplegia given through coronary ostia, septal myectomy was done transaortically. Apical hypertrophied part was addressed by opening the LV apex. Left ventricle was closed using hard Teflon buttressing the edge of LV opening. Aorta was also closed in two layers using 4-0 proline. De-airing was done through aortic root, and cross-clamp was released. Heart picked up in sinus rhythm without inotropic support. Hemostasis was achieved with protamine. Chest was closed after putting two mediastinal chest tubes and two right atrium and right ventricle pacing wires. Post-operative echocardiography showed no significant gradient across left ventricle outflow tract as well intracavitary gradients significantly came down with trivial MR, intact interventricular septum/inter arterial septum, good superior vena cava, and pulmonary vein (PV) flows. Gross examination of aortic soft tissue was studied for aortitis which gave no evidence of aortitis.

\section{DISCUSSION}

In 1971, Forker and Morgan [14] reported a case of idiopathic hypertrophic subaortic stenosis and an ostium secundum type ASD. 


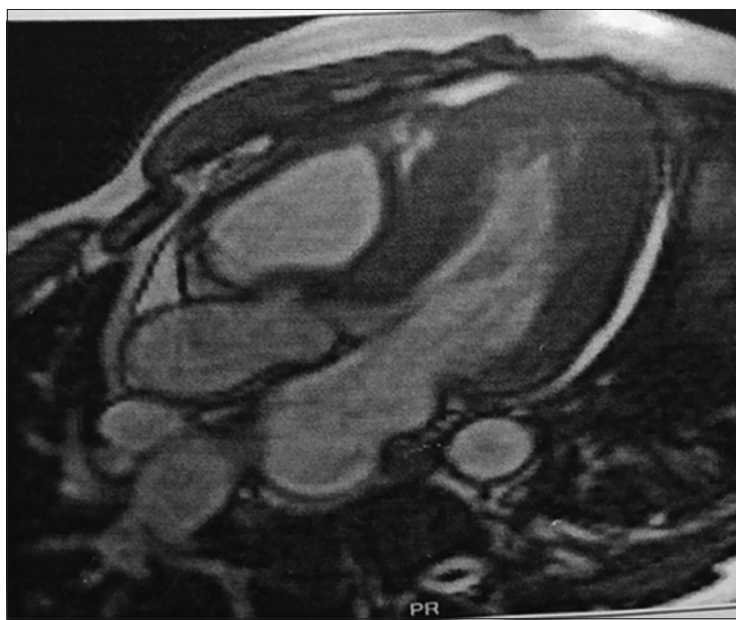

Fig. 1: Magnetic resonance imaging showing concentric hypertrophy with systolic arterial motion causing significant left ventricular outflow tract narrowing

Hernández-Reyes et al. [15] described a 36-year-old patient with non-obstructive septal hypertrophy and ostium secundum ASD demonstrated by transthoracic echocardiography and confirmed by transesophageal echocardiography of the septal defect. Long et al. [16] reported a case with association of ostium secundum type ASD and sinus venous type ASD as a very rare form. Smith et al. [17] defined a case with similar association in a patient who was later operated and ASD closure and septal myomectomy were performed. Morito et al. [18] described a case of ASD in apical HOCM associated with coronary spasm in 2004.

HOCM has been reported to have some different associations. Branco et al. [19] reported a case with non-obstructive septal hypertrophy and ostium secundum type ASD who was diagnosed by transthoracic and transesophageal echocardiography, and the diagnosis was confirmed by cardiac catheterization, and the defect was closed surgically. However, the coexistence of hypertrophic obstructive cardiomyopathy, sinus venous ASD, PAPVC, and CAD is uncommon.

Partial anomalous pulmonary venous drainage occurs in about $10 \%$ of patients with atria, septal defect, whether this be a sinus venous type, a centrally situated secundum defect, or a large posterior defect with no posterior margin (pseudo-anomalous right PVs). The surgical anatomy of the sinus venous defect was first described in detail by Swan et al. [20] who recognized the absence of a posterior rim and upper margin and the association with partial anomalous pulmonary venous drainage. It was important to recognize the condition before operation since it made repair difficult, and cardiopulmonary bypass was always required to achieve a satisfactory result. The prevalence of SVD varies from $2 \%$ to $10 \%$ of patients with ASD [21,22].

In our case, the clinical symptoms of breathlessness and exertional syncope could be related to LV diastolic dysfunction as well as his hemodynamic instability created by HOCM and SVASD. The gradient in the mid-ventricular cavity might lead to decrease in cardiac output, and increased afterload, and reduced diastolic perfusion then could cause those symptoms of the patient. The syncope which precipitated on exertional was thought to be related with an infrequent interval of ventricular tachycardia, increase of mid-ventricular obstruction with exercise, and cerebral hypoperfusion.

\section{CONCLUSION}

Hence, whenever HOCM is proved in a patient, as it is a congenital anomaly, it is important to keep in mind that another accompanied congenital defect could be present.

\section{REFERENCES}

1. Maron BJ, McKenna WJ, Danielson GK, Kappenberger LJ, Kuhn HJ, Seidman CE, et al. American College of Cardiology/European Society of Cardiology clinical expert consensus document on hypertrophic cardiomyopathy. A report of the American College of Cardiology Foundation Task Force on Clinical Expert Consensus Documents and the European Society of Cardiology Committee for Practice Guidelines. J Am Coll Cardiol 2003;42(9):1687-713.

2. Alcalai R, Seidman JG, Seidman CE. Genetic basis of hypertrophic cardiomyopathy: From bench to the clinics. J Cardiovasc Electrophysiol 2008;19:104-10.

3. Maron BJ, Towbin JA, Thiene G, Antzelevitch C, Corrado D, Arnett $\mathrm{D}$, et al. Contemporary definitions and classification of the cardiomyopathies: An American Heart Association Scientific Statement from the Council on Clinical Cardiology, Heart Failure and Transplantation Committee; Quality of Care and Outcomes Research and Functional Genomics and Translational Biology Interdisciplinary Working Groups; And Council on Epidemiology and Prevention. Circulation 2006;113(14):1807-16.

4. Bos JM, Towbin JA, Ackerman MJ. Diagnostic, prognostic, and therapeutic implications of gene testing for hypertrophic cardiomyopathy. J Am Coll Cardiol 2009;54(3):201-11.

5. Dantuluri S, Kumar RS, Kumar MA, Basha SJ. Diagnostic value of serum n-terminal pro b-type natriuretic peptide (nt-probnp) for left ventricular dysfunction in hypertensive cases. Asian J Pharm Clin Res 2017;10(4):391-3

6. Maji D, Samanta S. A review on the role of peroxisome prolifertoractivated receptor- $\gamma$ agonists and hybrids in Type 2 diabetes and cardiomyopathy. Asian J Pharm Clin Res 2015;8(2):26-31.

7. Maron BJ. Hypertrophic cardiomyopathy: A systematic review. JAMA 2002;287(10):1308-20

8. Rickers C, Wilke NM, Jerosch-Herold M, Casey SA, Panse P, Panse N, et al. Utility of cardiac magnetic resonance imaging in the diagnosis of hypertrophic cardiomyopathy. Circulation 2005;112(6):855-61.

9. Maron MS, Maron BJ, Harrigan C, Buros J, Gibson CM, Olivotto I, et al. Hypertrophic cardiomyopathy phenotype revisited at 50 years with cardiovascular magnetic resonance. J Am Coll Cardiol 2009;54(3):220-8

10. Olivotto I, Maron MS, Autore C, Lesser JR, Rega L, Casolo G, et al. Assessment and significance of left ventricular mass by cardiovascular magnetic resonance in hypertrophic cardiomyopathy. J Am Coll Cardiol 2008;52(7):559-66.

11. Harris KM, Spirito P, Maron MS, Zenovich AG, Formisano F, Lesser JR, et al. Prevalence, clinical profile, and significance of left ventricular remodeling in the end-stage phase of hypertrophic cardiomyopathy. Circulation 2006;114(3):216-25

12. Maron MS, Finley JJ, Bos JM, Hauser TH, Manning WJ, Haas TS, et al. Prevalence, clinical significance, and natural history of left ventricular apical aneurysms in hypertrophic cardiomyopathy. Circulation 2008;118(15):1541-9.

13. Maron MS, Olivotto I, Zenovich AG, Link MS, Pandian NG, Kuvin JT, et al. Hypertrophic cardiomyopathy is predominantly a disease of left ventricular outflow tract obstruction. Circulation 2006;114(21):2232-9.

14. Forker AD, Morgan JR. Hypertrophic subaortic stenosis with ostium secundum atrial septal defect. Chest 1971;60(5):512-5.

15. Hernández-Reyes $\mathrm{P}$, Espinola-Zavaleta $\mathrm{N}$, Vargas-Barrón J, Romero-Cárdenas A, Roldán-Gómez J, Keirns C. Nonobstructive asymmetrical septal hypertrophy and ostium secundum-type atrial septal defect. Echocardiography 2000;17(8):725-9.

16. Long JL, Nourissat JL, Normand J, Michaud P. Association of an interauricular communication of the sinus venosus type with obstructive myocardiopathy. Surgical treatment. Arch Mal Coeur Vaiss 1984;77(2):222-7.

17. Smith DC, Vieweg WV, Folkerth TL, Hagan AD. Idiopathic hypertrophic subaortic stenosis with ostium secundum atrial septal defect: Successful surgical correction. Chest 1975;68(2):246-8.

18. Morito N, Ogawa M, Matsuo S, Mihara H, Miyoshi K, Yahiro E, et al. Atrial septal defect in apical hypertrophic cardiomyopathy associated with coronary spasm. Int J Cardiol 2004;93(2-3):339-42.

19. Branco LM, Quininha J, Roquette J, Madeira H, Coelho EM, Bento R, et al. Hypertrophic non-obstructive cardiomyopathy associated with interauricular communication. Report of a case. Rev Port Cardiol 1990;9:449-53.

20. Swan HJ, Kirklin JW, Becu LM, Wood EH. Anomalous connection of rightpulmonary veins to superior vena cava with interatrial communications: Hemodynamic data in eight cases. Circulation 
1957:16(1):54-65

21. Lewis FJ, Taufic M, Varco RL, Niazi S. The surgical anatomy of atrial septal defects: Experiences with repair under direct vision. Ann Surg
1955;142(3):401.

22. Davia JE, Cheitlin MD, Bedynek JL. Sinus venosus atrial septal defect: Analysis of fifty cases. Am Heart J 1973;85(2):177-85. 